\title{
Pattern of leukaemia in Basrah
}

\author{
Omran S. Habib ${ }^{a}$, Asaad AA Khalaf ${ }^{b}$, Jenan G. Hasan ${ }^{c}$, Laith A. Alrudainy ${ }^{d}$, Hasson M. Hasson ${ }^{b}$, Husam M. Salih ${ }^{e}$, \\ Mohammed K. Dorki ${ }^{\mathrm{e}}$ \\ ${ }^{\text {a} P r o f e s s o r ~ o f ~ E p i d e m i o l o g y ~ a n d ~ H e a l t h ~ C a r e, ~}{ }^{\text {d}}$ Lecturer, Department of Community Medicine. ${ }^{\mathrm{C}}$ Assistant professor of Paediatric \\ Oncology, College of Medicine, University of Basrah. 'Internist and Medical Oncologist, Al-Sadr Teaching Hospital, Basrah. \\ 'Paeditrician, Basrah Maternity and Children Hospital, Basrah, Iraq. \\ Correspondence: Omran S. Habib ${ }^{\mathrm{a}}$. omran49_basmed@yahoo.com.
}

(Ann Coll Med Mosul 2013; 39 (2): 154-159).

Received: $16^{\text {th }}$ Oct. 2012; Accepted: $26^{\text {th }}$ May 2013.

\section{ABSTRACT}

Background: In Basrah, previous studies reported increased risk of certain cancers including leukaemia. Two important features were reported: a rise in the incidence rate of leukaemias in children and an age shift towards younger children. These studies were limited by the incompleteness of data they used.

Objectives: This paper is intended to present a profile of leukaemia in Basrah over the years 2005-2008.

Methods: The cases of leukaemia presented in this paper represent all cases diagnosed, treated and registered in Basrah during the years 2005-2008. The cases were drawn from the pool of cancer registries in various health care institutions dealing with cancer using a case series study design. All available and verifiable cases were included in the study. Relevant incidence rates were calculated by dividing the average annual number of cases by mid-period population for each category used.

Results: During the four - year study period, it was possible to identify 608 cases of leukaemia; $56.4 \%$ were among males and $43.6 \%$ were among females. More than half of the cases $(52.8 \%)$ were from Basrah, $26.5 \%$ were from Thi Qar, $13.6 \%$ were from Missan, and $7.1 \%$ were from other governorates. The agespecific incidence rate in Basrah showed a bimodal distribution with higher rates at extreme ages. The crude incidence rate was 3.6 per 100000 population (3.9 per 100000 males and 3.2 per 100000 females). The age standardized incidence rate was 4.3 per 100000 males and 3.9 per 100000 females.

Conclusion: Leukaemia is a significant malignant disease in Basrah. The figures of incidence rate point towards an upward trend, but still comparable to the figures from other Gulf countries.

Keywords: Leukaemia, incidence, Basrah

$$
\begin{aligned}
& \text { طراز إبيضاض الام في البصرة } \\
& \text { عمران سكر حبيب*، أسعد عبد الامير خلف**، جنان غالب حسن***، ليث عبد المجيد الرديني*، حسون مهدي حسون**، الرئ }
\end{aligned}
$$

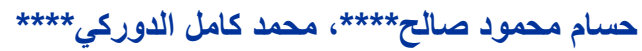

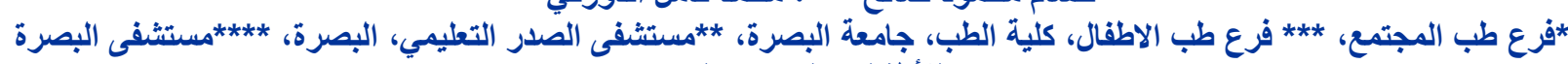

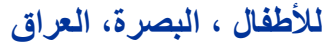

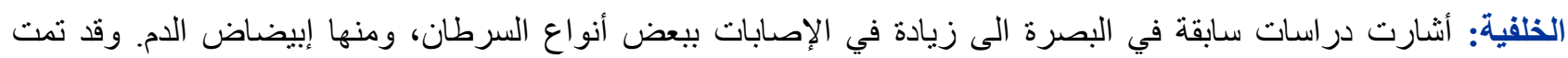

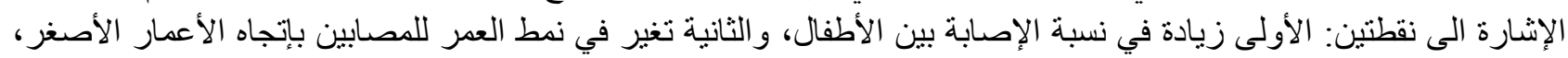

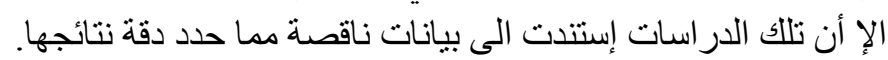

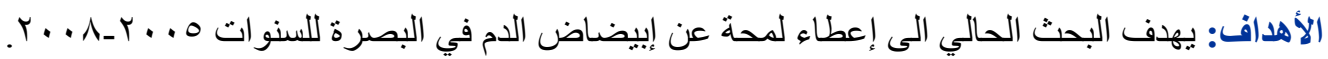

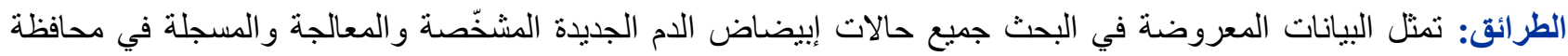

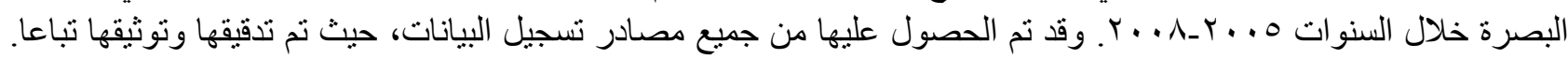

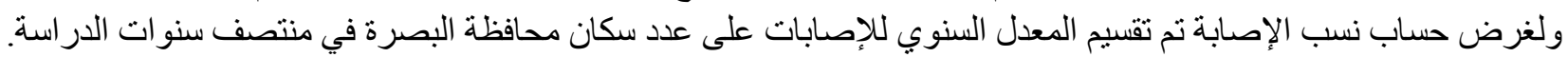




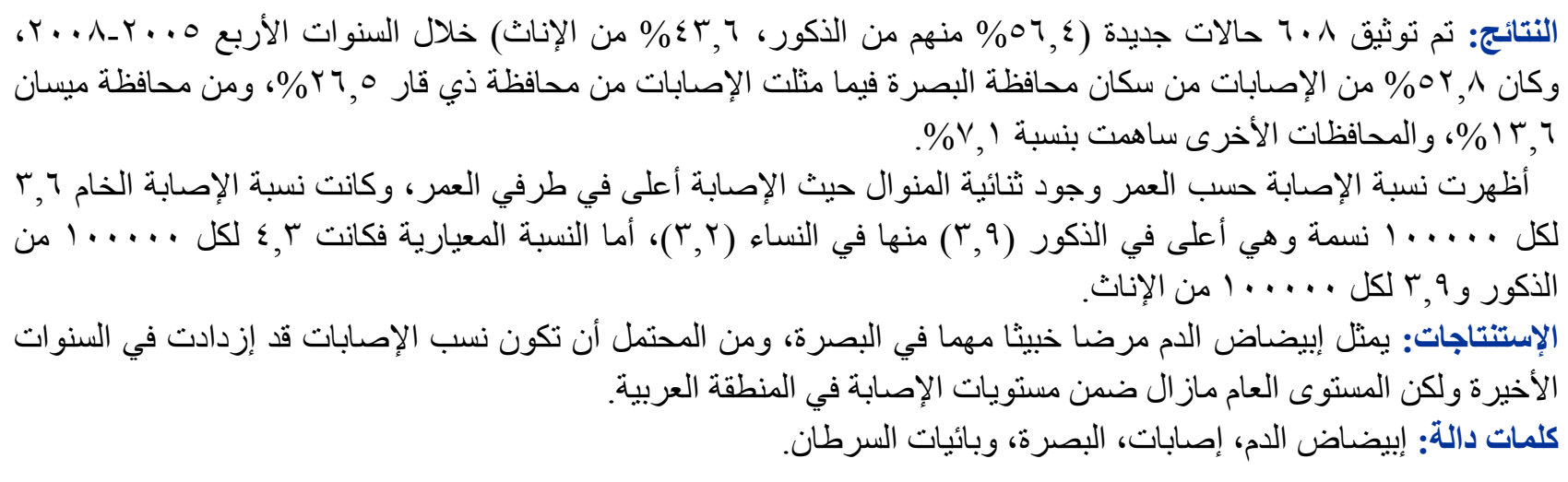

\section{INTRODUCTION}

$\mathrm{H}$ aematological malignancies comprise a collection of heterogeneous conditions, all originating from cells of the bone marrow and the lymphatic system. There are three major groups: leukaemias, lymphomas, and plasma cell neoplasms. ${ }^{1}$ Leukaemia is a disease resulting from the neoplastic proliferation of haemopoietic or lymphoid cells. It results from a mutation in a single stem cell, the progeny of which form a clone of leukaemic cells. Often there is a series of genetic alterations rather than a single event. Genetic events contributing to malignant transformation include inappropriate expression of oncogenes and loss of function of tumor suppressor genes. The cell in which the leukaemic transformation occurs may be a lymphoid precursor, a myeloid precursor or a pluripotent stem cell capable of differentiating into both myeloid and lymphoid cells. ${ }^{2}$

Leukaemias are broadly divided into: (i) acute leukaemia, which, if untreated, leads to death within weeks or months; and (ii) chronic leukaemia, which, if untreated lead to death within months or years. They are further subdivided according to which kind of blood cells is affected into lymphoid or myeloid. ${ }^{2}$ Accordingly, the major four types are acute lymphoblastic leukaemia (ALL), acute myeloblastic leukaemia (AML), chronic lymphoblastic leukaemia (CLL) and chronic myeloblastic leukaemia (CML).

Worldwide, over 250000 people are diagnosed with leukaemia each year, accounting for $2.5 \%$ of all cancers. The incidence of leukaemia, however, is variable across the world. The lowest incidence rate is reported in Sub-Saharan Africa and the highest in Australia and new-Zealand. All age groups can be affected; leukaemias are the most common pediatric tumors $(35 \%$ of cancers in children aged 0-14 years). Most cases, however, occur in older adults; more than half after 65 years of age. ${ }^{1,3}$

In the Arab areas of Asia, studies are limited on leukaemia particularly regarding risk factors but it seems an important and a growing problem. ${ }^{4}$

Suspicions of increased leukaemia incidence in the region of Basrah have been raised since 1995, presumably as consequence of the use of ammunition with depleted Uranium in the Gulf wars. Previous studies reported increased risk of certain cancers including leukaemia. Two important features were reported: a rise in the incidence rate of leukaemia and lymphoma in children and an age shift towards younger children., 50 quote some figures, the incidence rate of leukaemia has increased from 2.3 in 1995 to 3.2 per 100000 population in 2005. However the risk factors associated with such increased disease risk have not been tackled with analytical epidemiological studies. An attempt was made to relate these changes to environmental exposure particularly to depleted uranium but the evidence was inconclusive. ${ }^{6}$

The present study is an attempt to present a profile on all cases of leukaemia diagnosed, treated or registered in Basrah over a four-year period 2005-2008.

\section{PATIENTS AND METHODS}

The cases of leukaemia presented in this paper represent all cases diagnosed, treated and registered in Basrah during the years 2005-2008. The cases were drawn from the pool of cancer registries in various health care institutions dealing with cancer. The study is part of a comprehensive 
project on "cancer and environment in Basrah". From the pool of cases available to the Basrah Cancer Research Group (BCRG), all verifiable cases with definite diagnosis of any subtype of leukaemia were compiled and entered into an SPSS computer programme for statistical analysis. A total of 608 cases were identified and used in this paper. Included are cases with verified and ascertained diagnosis from first week of January 2005 up to December $31^{\text {st }}, 2008$.

Cases identified by various sources were typed first on excel sheets in most centers or identified from their original documents and typed by members of BCRG on excel sheet. Then, all the excel files were pooled together in one file and matched and checked for any repetition resulting from cases being reported by more than one source.

The ascertainment of cases was based on morphological methods of diagnosis. The results are presented for all registered cases first, then specific rates are presented for cases from inhabitants of Basrah province.

Information related to population of Basrah was based on data available from Basrah Health Authorities and from the Statistical Office in Basrah. Incidence rates were calculated by dividing the average annual number of new cases by mid-period population for each category used, then multiplying by 100000 . Age standardized incidence was derived using the World standard population by the direct method. ${ }^{3}$

\section{RESULTS}

\section{Characteristics of cases}

The distribution of cases registered in Basrah is shown in Table 1. Male cases were more frequent than female cases accounting for $56.4 \%$ and $43.6 \%$ respectively. (Male:Female ratio $=1.29: 1$ ). More than half of the cases $(52.8 \%)$ were from Basrah, 26.5\% were from Thi Qar, 13.6\% were from Missan, and $7.1 \%$ from other governorates.

Regarding years of registration, the percentage of cases registered during 2005 was the lowest (18.8\%). In both 2006 and 2007, a relatively higher registration was reported $(28.5 \%$ and $28.6 \%$ respectively). The percentage declined in 2008 to $24.2 \%$.
Table 1. Characteristics of leukaemia cases registered in Basrah during 2005-2008.

\begin{tabular}{|c|c|c|}
\hline Characteristics & No. of cases & (\%) \\
\hline \multicolumn{3}{|l|}{ Sex } \\
\hline Male & 343 & 56.4 \\
\hline Female & 265 & 43.6 \\
\hline \multicolumn{3}{|l|}{ Place of residence } \\
\hline Basrah & 321 & 52.8 \\
\hline Thi Qar & 161 & 26.5 \\
\hline Missan & 83 & 13.6 \\
\hline Other governorates & 43 & 7.1 \\
\hline \multicolumn{3}{|l|}{ Year of Registration } \\
\hline 2005 & 114 & 18.8 \\
\hline 2006 & 173 & 28.5 \\
\hline 2007 & 174 & 28.6 \\
\hline 2008 & 147 & 24.2 \\
\hline Total & 608 & $100.1^{*}$ \\
\hline
\end{tabular}

The main types of leukaemia

Figure 1 shows that the most frequent type of leukaemia is ALL which represents $69 \%$ of all registered cases followed by $A M L$ representing $16 \%$ and the lowest frequent type is CLL forming $5 \%$.

Figure 2 shows a comparison of the relative frequency of types for children and adults. The most frequent type of leukaemia in children is ALL which constituted $82 \%$ followed by AML $13 \%$. Among adults, ALL again is the most frequent type $(60 \%)$ followed by AML (16\%), CML (14\%) and the lowest is CLL (10\%).

\section{Age by type of cases}

The mean and median ages are different according to the different types of leukaemia as shown in Table 2.

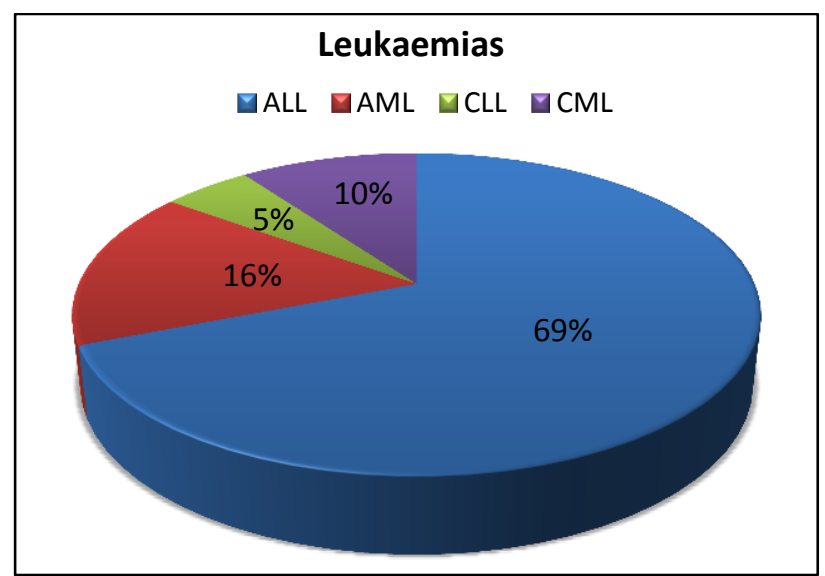

Figure 1. The-percentage distribution of the main 4 types of leukaemia. 


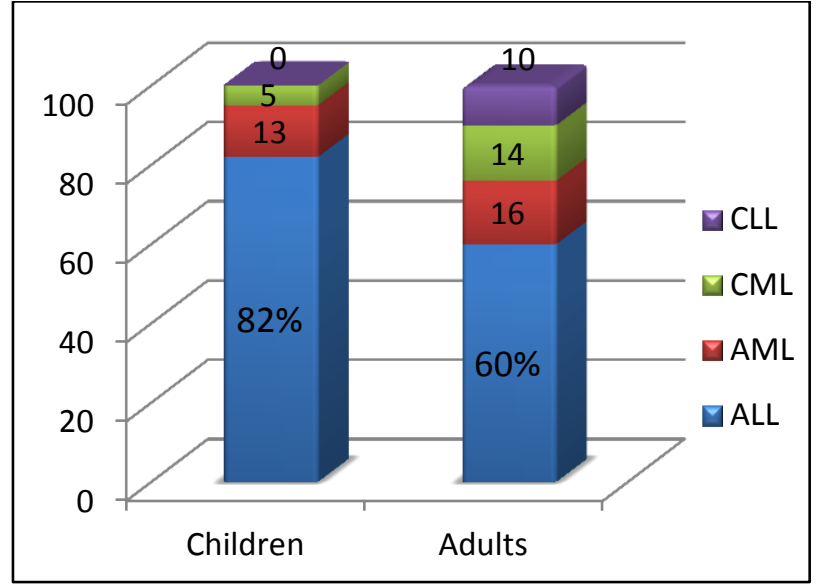

Figure 2. The percentage distribution of the four types of leukaemia in children (below 15 year) and adults.

Table 2. Mean and median age (years) by types of leukaemia.

\begin{tabular}{lcc}
\hline Type of leukaemia & Mean Age+ SD & Median age \\
\hline ALL & $19.6+18.5$ & 14 \\
CLL & $58.3+16.2$ & 60 \\
AML & $28.4+21.9$ & 22 \\
CML & $38.6+22.5$ & 40 \\
\hline
\end{tabular}

\section{Leukaemia in Basrah: Risk by sex}

Table 3 shows the distribution of incidence rate of leukaemia in Basrah according to age and sex. A total of 178 cases were registered among males over the period 2005-2008 and the average number per year was about 45 cases. This gives a crude annual incidence rate of 3.9 per 100000 males and an age standardized incidence of 4.3 per 100000 males. The incidence rate is high in male children aged less than 15 years then it declines with advancing age until the middle of the fifth decade when it rises again reaching a maximum rate of 29.2 per 100000 males aged 75 years and older. For females a total of 143 cases were registered over the period 2005-2008 and the average number per year was about 36 cases. This gives a crude annual incidence rate of 3.2 per 100000 females and an age standardized incidence rate of 3.9 per 100000 females. The incidence rate is high in children aged less than 15 years then it declines with advancing age until the middle of the fifth decade when it rises again with advancing age reaching a peak of 16.8 per 100000 in the age group 70-74 years. The results suggest a bimodal distribution in both sexes. The major mode is in the $8^{\text {th }}$ decade of age and less prominent mode is seen in children aged less than 10 years.
Subtypes of leukaemia in Basrah in comparison to selected countries

Table 4 presents a comparative data on subtypes in Basrah, Kuwait and Saudi Arabia (Riyadh). Although the overall pattern is more or less similar, clear discrepancies do exist particularly in ALL which is much more common in Basrah. The agespecific incidence rates in Basrah are similar to those in Jordan and America in children and young adults but lower in Basrah compared to Jordan and America from the fifth decade of age onwards as shown in Figure 3.

Table 3. Incidence rates (IR) of leukaemia in Basrah during 2005-2008 by age and sex.

\begin{tabular}{|c|c|c|c|c|}
\hline \multirow[b]{2}{*}{$\begin{array}{l}\text { Age in } \\
\text { years }\end{array}$} & \multicolumn{2}{|c|}{ Males } & \multicolumn{2}{|c|}{ Females } \\
\hline & $\begin{array}{c}\text { No. of } \\
\text { cases in } \\
4 \text { years }\end{array}$ & $\begin{array}{l}\text { IR per } \\
100000 \\
\text { per year }\end{array}$ & $\begin{array}{l}\text { No. of } \\
\text { cases in } \\
4 \text { years }\end{array}$ & $\begin{array}{l}\text { IR per } \\
100000 \\
\text { per year }\end{array}$ \\
\hline$<5$ & 32 & 5.6 & 25 & 4.6 \\
\hline $5-9$ & 38 & 7.0 & 25 & 4.6 \\
\hline $10-14$ & 19 & 3.6 & 11 & 2.2 \\
\hline $15-19$ & 14 & 2.9 & 11 & 2.4 \\
\hline $20-24$ & 10 & 2.2 & 7 & 1.6 \\
\hline $25-29$ & 6 & 1.4 & 8 & 1.8 \\
\hline $30-34$ & 7 & 1.8 & 3 & 0.9 \\
\hline $35-39$ & 7 & 2.4 & 10 & 3.5 \\
\hline $40-44$ & 2 & 1.0 & 3 & 1.2 \\
\hline $45-49$ & 9 & 4.7 & 4 & 2.3 \\
\hline $50-54$ & 6 & 4.1 & 8 & 4.4 \\
\hline $55-59$ & 6 & 5.7 & 6 & 5.4 \\
\hline $60-64$ & 9 & 9.4 & 8 & 12.0 \\
\hline $65-69$ & 2 & 3.6 & 6 & 15.0 \\
\hline $70-74$ & 3 & 8.2 & 6 & 16.8 \\
\hline $\begin{array}{l}75 \text { and } \\
\text { above }\end{array}$ & 8 & 29.2 & 2 & 5.0 \\
\hline Total & 178 & 3.9 & 143 & 3.2 \\
\hline
\end{tabular}

Age standardized incidence rate per 100000 (Male=4.3, Female $=3.9$ )

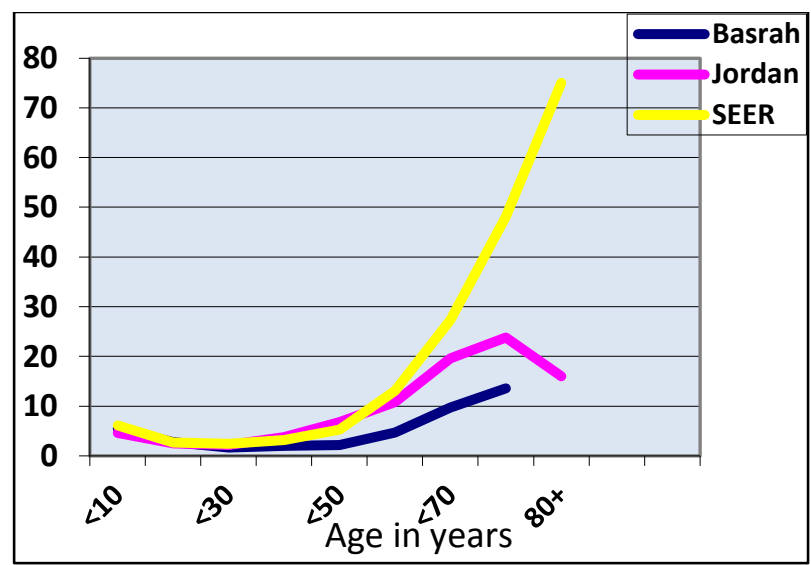

SEER $=$ statistical and epidemiological end results.

Figure 3. Comparison of age specific incidence rates in three registries. 
Table 4. Relative frequency (\%) of subtypes of leukaemia in Basrah, Kuwait and Riyadh.

\begin{tabular}{lcccc}
\hline \multicolumn{1}{c}{ Region } & ALL (\%) & CLL & AML & CML \\
\hline $\begin{array}{l}\text { Basrah } \\
\text { (2005-2008) }\end{array}$ & 69.0 & 5.0 & 16.0 & 10.0 \\
Kuwait (1994) & 44.2 & 8.6 & 32.4 & 14.8 \\
Riyadh (1991) & 24.23 & 18.77 & 37.54 & 19.11 \\
\hline
\end{tabular}

\section{DISCUSSION}

In Basrah, which was subjected to massive environmental damage from wars, economic embargo and local events, cancer and its determinants became a hot issue. Claims and counter claims are plenty. ${ }^{8-13}$ Three basic questions remained unanswered; what is the incidence rate of cancer (including leukaemia) in Basrah? Is there an adequate evidence that cancer has increased in Basrah during the last two decades? If there is increasing cancer risk with time, what are the possible explanations?

Leukaemia is one of the top ten cancers both in males and females. ${ }^{7}$ This study took the advantage of a unique registry of almost all cases diagnosed and treated in Basrah over the period of 20052008 , to provide an epidemiological profile of leukaemia in Southern part of Iraq and in particular to present a reliable estimates of incidence of leukaemia in Basrah. These results may be considered as the basis for comparison in any attempt to examine the time trend of cancer in the past or in the future.

Leukaemia in Southern part of Iraq, as other haematological malignancies worldwide, showed slightly male preponderance (M:F was 1.29:1). The registered cases were distributed geographically mainly over three provinces with more than half of the cases $(56.4 \%)$ from Basrah. During the period 2005-2008, the median age at diagnosis for leukaemia was 18 years for males and 22 years for females. This clearly points out to the distinct feature of younger age affected as compared with, for example, 67 years median age at diagnosis of leukaemia in US. ${ }^{13} \mathrm{It}$, in turn, reflects two facts; the first is the structure of population at risk of leukaemia in general, people aged 50 years and older represent just above $10 \%$ of all leukaemia cases as compared to more than $70 \%$ of statistical and epidemiological end results (SEER) population, ${ }^{13}$ the second fact is that the risk of leukaemia is high in children younger than 15 years.
The occurrence of subtypes of leukaemia was analyzed in the present study also. Acute lymphoblastic leukaemia was the most frequent type overall and both in children and adult population $(69 \%, 82 \%$ and $60 \%$ respectively), followed by AML (16\%, 13\% and 16\%), CML (10\%, $5 \%$ and $14 \%$ ). The lowest fraction was for the subtype CLL (5\%). This finding also could add supporting evidence that the risk of leukaemia is higher in younger ages than in elderly. In Kuwait, ${ }^{14}$ Al-Bahar et al, during the 1980s also reported that ALL as the most frequent subtype (44.2\%) followed by AML (32.4\%), CML (14.8) and the least was CLL $(8.6 \%)$, the pattern of occurrence is somewhat different from Saudi Arabia. ${ }^{15}$ In the UK, almost one third of the cases were $\mathrm{AML}$ and around a further third were CLL; CML and ALL each accounted for one tenth of the cases. ${ }^{16}$ Chronic lymphoid leukaemia which constitutes more than $30 \%$ of all leukaemia in western countries, is extremely rare in Asian countries like Japan and China (10\% of all leukaemias). ${ }^{17}$ If the age structure of the present study population was considered as compared to longevity of East Asian countries, the figure of $5 \%$ seems to be acceptable. However, the true incidence and the relative frequency of CLL are slightly higher because of the initial benign clinical course of the disease and probably some of the patients were not seeking medical advice and thus have not been registered. This also may be true in developed countries, for example in the USA the actual incidence of CLL could be higher than the estimated from tumor registries. ${ }^{17}$ However, CLL is a disease of elderly in the present study which is comparable with Western countries.

Acute myeloid leukaemia (AML) is the commonest acute leukaemia in adults and is rare in children and young adults. The incidence of AML increases with age and ranges from 0.7 to 3.9 cases per 100000 between 0 and 60 years and from 6.7 to 19.2 cases per 100000 above 60 years with a median of more than 70 years. ${ }^{18}$ In the present study, it ranked second after ALL with interestingly low median age of 22 years as compared with average age of 30 among Omanis adults and children ${ }^{19}$ and 34 years of adult Egyptians. ${ }^{20}$

The incidence of $\mathrm{CML}$ is variable but increases with age. The median age differs between cancer 
registries and clinical trials by $10-20$ years. ${ }^{21}$ The median age of CML patients in the present study is 40 years.

Leukaemia in Basrah, as in other Gulf countries ${ }^{22}$ (R GCC) is more common when compared with the worldwide incidence. It is the $5^{\text {th }}$ most common cancer ${ }^{7}$ and accounts for $4.3 \%$ of all cancers in Basrah with male:female ratio of 1.24:1. The age standardized incidence rates were 4.3 and 3.9 per 100000 population for males and females respectively. This rate is intermediate among other Gulf States; Bahrain had the highest incidence among males with ASR of 8.1 followed by Qatar and Kuwait. The lowest incidence was in UAE males (ASR was 2.9). In females, Qatar had the highest incidence (ASR was 4.7) followed by Bahrain and Kuwait with 4.6 each. The lowest incidence was among Saudi women (ASR was 2.9). ${ }^{7,22}$

According to age-specific incidence rates, leukaemia in Basrah has bimodal distribution with first peak at pediatric age group of $<15$ year and the highest peak after age of 70 and this is true for both males and females. However, the incidence rate is still similar to the figures from neighbouring countries like Jordan as well as SEER until the fourties and then it declines, ${ }^{23}$ as shown in Figure 3.

\section{REFERENCES}

1. Rodriguez-Abreu D, Bordoni A, Zucca E. Epidemiology of hematological malignancies. Annals of Oncology 2007;18(Suppl 1):13-18.

2. Barbara J. Bain. Leukaemia Diagnosis. $3^{\text {rd }}$ ed. Blackwell Publishing; 2003. p. 1.

3. Parkin DM, Bray F, Ferlay J, Pisani P. Global cancer statistics. Cancer J Clin 2005; 55: 74-108.

4. Salim El, Moore MA, Kayed S, Al-Lawati JA, AlSayyad J, Bawazir A, et al. Cancer epidemiology in the Arab Region: Past, present and future. APJCP 2009; 10: 27-44.

5. Habib OS, Al-Ali JK, Al-Wiswasi MK, Ajeel NAH. The Burden of cancer in Basrah: The state of the art. Basrah 2006. [cited 2011 July]. Available from: URL:http://www. Basmedcol.com.

6. Yacoub AAH, Al-Sadoon IO, Hassan GG, Muffid AIHemadi. Incidence and pattern of malignant disease among children in Basrah with specific reference to leukaemia during the period 1990-1998. Medical journal of Basrah University 1999;17: 27-34.

7. BCRG. Cancer in Basrah: Epidemiological analysis of incident cancer 2005-2008. Basrah Cancer Research Group, Dar-Al-Kutub for press and publication, Basrah 2009.

8. Habib Os, Al-Diab JMA, Mohsin A, Elwe WM, Hassan JG, Al-Haroun SS, Al-Emara KAS. Experience and outcome of population-based cancer registration in Basrah-Southern Iraq in four years (2005-2008). APJCP 2010;11:1151-1154.

9. Yacoub AAH, Al-Sadoon IO, Hassan GG and Muffid Al-Hemadi. Incidence and pattern of malignant disease among children in Basrah with specific reference to leukaemia during the period 1990-1998. The Medical journal of Basrah University 1999;17: 27-34.

10. Yacoub AAH, Ajeel NAH, Al-Wiswasy MK. Incidence and pattern of malignant diseases (excluding leukemia) during 1990- 1997. The Medical journal of Basrah University 1999;17:35-41.

11. Hassan Jk. Cancer in Basrah: Pattern and determinants with special emphasis on SCD and G6PD deficiency (A new hypothesis). Ph.D. thesis, University of Basrah 2003.

12. Fahey D. Science or Science Fiction: Facts, myths and propaganda in the debate over depleted uranium weapons. 2003 [cited 2007 March]. Available from: URL:http://www.danfahey.com/DanFahey/.

13. Ries LAG, Melbert D, Krapcho M, Stinchcomb DG, Howlader N, Horner MJ, et al. SEER Cancer Statistics Review, 1975-2005, National Cancer Institute. Bethesda, MD. [cited 2011 July]. Available from: URL:http://seer. cancer.gov/ csr/1975_2005/, based on November 2007 SEER data submission, posted to the SEER web site.

14. Al-Bahar S, Pardita R, Al - Muhannaha A, Al-Bahar $\mathrm{E}$. The epidemiology of leukemia in Kuwait. Leuk Res 1994; 18: 299 - 307.

15. Khan MQ, Shivarudrappa AS, Al-Bialy S, Al-Khawagi MZ, Al-Mofarreh M. Leukemia cases in central hospital, Riyadh (Saudi Arabia). J Indian Med Assoc 1991;89:3842.

16. Quinn MJ, Babb PJ, Brock A, Kirby L, Jones J. Cancer Trends in England and Wales 1950-1999. Studies on Medical and Population Subjects No. 66. London: The Stationery Office, 2001.

17. Linet MS, Devesa SS, Morgan GJ. The leukaemias in: Cancer epidemiology and prevention by Schottenfeld $D$ and Fraumeni J. $3^{\text {rd }}$ edition. New York: Oxford University Press; 2006. Chapter 44. p. 861-871.

18. Ries LA, Kosary CL, Hankey BF, Miller BA, Clegg LX, Edwards BK, eds. SEER Cancer Statistics Review, 1973-1996. NIH publication 99-2789. Bethesda, MD: National Cancer Institute; 1999.

19. Huxley H.M. Knox-Macaulay, Leonard C. Brown. Descriptive epidemiology of de novo acute leukaemia in the Sultanate of Oman. Leukemia Res2000;24:589-594. 20. El-Zawahry HM, Zeeneldin AA, Mohamed A, Samra MA. Cost and Outcome of Treatment of Adults with Acute Myeloid Leukemia at the National Cancer Institute-Egypt. Journal of the Egyptian Nat. Cancer Inst. 2007;19 (2):106-113

21. Rohrbacher M, Hasford J. Epidemiology of chronic myeloid leukaemia (CML). Best Practice \& Research. Clin Haematology 2009; 22: 295-302.

22. Al-Hamdan N, Ravichandran $\mathrm{K}$, Al-Sayyad J, et al. Incidence of cancer in Gulf Cooperation Council Countries, 1998-2001. Eastern Mediterranean Health Journal 2008; 15: 600-611.

23. Freedman LS, Barchana M, Al-Kayed S, et al. A comparison of population-based cancer incidence rates in Israel and Jordan. Eur J Cancer Prev 2003;12 (5): 359-365. 